\title{
Slow Salivary Secretory IgA Maturation May Relate to Low Microbial Pressure and Allergic Symptoms in Sensitized Children
}

\author{
MALIN FAGERÅS, SARA TOMIČIĆ, TIIA VOOR, BENGT BJÖRKSTÉN, AND MARIA C. JENMALM
}

Department of Clinical and Experimental Medicine [M.F., S.T., M.C.J.], Linköping University, Linköping SE-581 85, Sweden; Children's Clinic of Tartu University Clinics [T.V.], 51014 Tartu, Estonia; Institute of Environmental Health [B.B.], Karolinska Institutet, SE-171 77 Stockholm, Sweden

\begin{abstract}
It is unknown why allergic symptoms do not develop in all sensitized children. We analyzed prospectively the postnatal secretory $\operatorname{IgA}$ (SIgA) development and whether high SIgA levels would protect sensitized infants from developing allergic symptoms. Salivary total IgA and SIgA levels were determined by ELISA, and allergy development was investigated at 3, 6, and 12 mo and at 2 and $5 \mathrm{y}$ in two birth cohorts in Estonia $(n=110)$ and Sweden $(n=91)$, two geographically adjacent countries with different living conditions and allergy incidence. Total and SIgA levels increased with age, reaching adult levels at the age of 5. Virtually, all salivary $\operatorname{IgA}$ in Estonian children was in the secretory form, while a major part of $\operatorname{IgA}$ in Swedish saliva lacked the secretory component up to $2 \mathrm{y}$ of age. In Sweden, high levels of salivary IgA without secretory component correlated inversely with house dust endotoxin levels. High SIgA levels were associated with less development of allergic symptoms in sensitized Swedish children. In conclusion, postnatal maturation of the salivary SIgA system proceeds markedly slower in Swedish than Estonian children, possibly as a consequence of low microbial pressure. SIgA may limit allergy-mediated tissue damage at mucosal surfaces in sensitized individuals. (Pediatr Res 70: 572-577, 2011)
\end{abstract}

$\mathrm{M}$ ucosal surfaces are the main ports of entry for most environmental antigens. The primary humoral mediators of mucosal immunity are secretory $\operatorname{IgA}(\operatorname{SIgA})$ and secretory IgM (SIgM), preventing adherence and penetration of antigens through the mucosal epithelium (1). As their polymeric form with an attached secretory component (SC) makes them resistant to cleavage by proteolytic enzymes, they are well suited for surface protection (1). Mucosal SIgA antibody responses are noninflammatory and are induced by immunoregulatory and IgE-inhibitory cytokines, such as TGF- $\beta$ and IL-10 (1). An efficient mucosal immune response is a prerequisite for health, because the various mucosal sites are favored as portals of entry by potentially pathogenic antigens and allergens. At birth, only traces of SIgA are found

Received March 25, 2011; accepted June 26, 2011.

Correspondence: Maria Jenmalm, Ph.D., Department of Clinical \& Experimental Medicine/AIR pl 10, Faculty of Health Sciences, Linköping University, SE-581 85 Linköping Sweden; e-mail: maria.jenmalm@liu.se

Supported by grants from the Swedish Research Council, the National Heart and Lung Association, The Vårdal Foundation for Health Care Sciences and Allergy Research, the National Swedish Association against Allergic Diseases, and the County Council of Östergötland.

The authors report no conflicts of interest. in human exocrine glands, and adult levels are not reached until several years later (2).

Atopic diseases are characterized by high and prolonged circulating IgE antibody responses to allergens (3). A still unsolved conundrum, however, is why some sensitized children do not develop clinical allergy symptoms. We have previously reported that skin prick test (SPT)-positive infants without any clinical symptoms of allergy have higher levels of salivary SIgA than those who manifest symptoms (4). Although there is no clear association between mucosal $\operatorname{IgA}$ production and development of allergic disease, it is conceivable that high levels of SIgA in the mucosa may prevent allergen absorption and also possibly interfere with the interaction between allergen and IgE antibodies in sensitized individuals, thereby preventing the development of allergic symptoms. High salivary SIgA levels may also reflect a more mature mucosal immune system (2). Recently, high fecal IgA levels at 6 mo were reported to be associated with a reduced risk to develop IgE-associated disease (5).

The prevalence of allergic diseases has increased considerably in industrialized countries during the last decades (6). Results derived from studies comparing the incidence of atopic diseases in countries of Western and Eastern Europe $(7,8)$ indicate that the increase is due to environmental factors associated with an affluent lifestyle. Decreased and/or altered microbial exposure because of e.g. improved hygiene, less infections, antibiotic treatment, and altered gut microbiota has been suggested to account for the increase of atopic diseases (9). The latter suggestion is supported by studies showing differences in the composition and diversity of the gut microbiota between allergic and nonallergic infants (10-13) and between infants living in countries with a low (Estonia) and high (Sweden) allergy prevalence (14). Moreover, growing up in an environment with heavy continuous external microbial exposure, e.g. farms, reduces the risk to develop allergic diseases (15). Higher levels of lipopolysaccharide (LPS) from the cell wall of Gram-negative bacteria were found in house dust collected from farming than from nonfarming households (16). Furthermore, we have previously shown higher LPS levels in house dust from Estonian than from Swedish homes

Abbreviations: EU, endotoxin units; LPS, lipopolysaccharide; pIgR, polymeric immunoglobulin receptor; SC, secretory component; SIgA, secretory IgA; SPT, skin prick test 
and that high LPS levels were associated with less atopy in Swedish infants (17). It is not known whether early microbial exposure affects the maturation of mucosal IgA responses, however, or if the postnatal maturation process differs among infants living in different environments.

The aim of this study was to investigate the development of mucosal immunity in Estonian and Swedish children followed up from birth to $5 \mathrm{y}$ of age, relating the IgA levels in saliva to development of sensitization, allergic disease, infections, and environmental endotoxin exposure.

\section{METHODS}

Subjects. This study comprised 110 Estonian and 91 Swedish children participating in a prospective study regarding development of allergic disease in relation to environmental factors. The study was approved by the Ethics Review Committee on Human Research of the University of Tartu and the Human Research Ethics Committee at the Faculty of Health Sciences, Linköping University. The parents of all children gave their written informed consent. The Estonian children were born during the period February 1997 to June 1998 and the Swedish children were born between March 1996 and March 2000. The children were followed up from birth to $5 \mathrm{y}$ of age as described in detail elsewhere (18). Briefly, at 3, 6, and 12 mo and at 2 and 5 years of age, the parents answered questionnaires regarding e.g. allergic symptoms, diarrhea, upper and lower respiratory infections, antibiotic treatment, and breastfeeding (Table 1). Furthermore, the children were clinically examined either by a pediatrician or an experienced allergy research nurse; SPTs were performed and saliva and blood samples were obtained. Atopic dermatitis was defined as pruritic, chronic, or chronically relapsing noninfectious dermatitis with typical features and distribution. Asthma was defined as three or more episodes of bronchial obstruction during the last 12-month period, at least once verified by a physician. Allergic rhinitis/conjunctivitis was diagnosed after appearing at least twice within $1 \mathrm{~h}$ after exposure to a particular allergen and not related to infections. Urticaria was defined as allergic if it appeared at least twice within $1 \mathrm{~h}$ after exposure to a particular allergen. The incidence of allergic symptoms is presented in Table 2 .

SPTs were done at all follow-ups in Estonia, whereas in the Swedish children they were randomly selected to be done either at 3 mo in half of the cohort or 6 mo in the remaining half of the cohort, and then at 12 and $24 \mathrm{mo}$ and $5 \mathrm{y}$ of age. SPTs were performed in duplicate at the volar aspects of the forearms with fresh skimmed cow's milk and thawed egg white at all follow-ups. At $12 \mathrm{mo}$, the children were also tested with cat allergen extract and in Estonia also with mite allergen extract (Dermatophagoides pteronyssinus). At 2 and $5 \mathrm{y}$, birch and timothy were added to the panel and in Estonia also cockroach (Blatella germanica) allergen. All extracts were standardized allergen extracts from ALK (Soluprick, ALK, Hørsholm, Denmark), except the cockroach extract, which was from Bayer (Spokane, WA). Histamine hydrochloride, 10 $\mathrm{mg} / \mathrm{mL}$, was used as positive control and glycerol as negative. The test was regarded as positive if the mean diameter of one of the wheals was at least $3 \mathrm{~mm}$. The incidence of positive SPT is presented in Table 2.

The Swedish children were further categorized as sensitized based on the presence of a positive SPT and/or detectable circulating allergen-specific IgE antibodies. This definition is not applicable in the Estonian children, because low levels of circulating IgE antibodies are commonly detected and are poorly related to allergy and SPT positivity (18). The presence of $\operatorname{IgE}$ antibodies in egg white and $\beta$-lactoglobulin were determined in serum samples collected at all follow-ups up to $24 \mathrm{mo}$, and $\mathrm{IgE}$ antibodies to cat and birch allergens were analyzed at 12 and 24 mo by a commercial chemiluminescence method, according to the recommendations of the manufacturer (Magic Lite, ALK). Blood samples were drawn from the Swedish children either at 3 mo in half of the cohort or $6 \mathrm{mo}$ in the remaining half of the cohort, and then at 12 and $24 \mathrm{mo}$ and $5 \mathrm{y}$ of age. Nine Swedish infants were sensitized at $3 \mathrm{mo}, 14$ at $6 \mathrm{mo}, 21$ at $12 \mathrm{mo}$, and 18 at 24 mo. The cumulative number up to that age was 30 .

Saliva samples. Nonstimulated saliva samples were collected at all followups from the buccal cavity, using a hand pump connected to a thin plastic tube and immediately frozen and kept at $-20^{\circ} \mathrm{C}$. Before analysis, the samples were heated at $56^{\circ} \mathrm{C}$ for $30 \mathrm{~min}$ and then centrifuged at $5000 \mathrm{~g}$ for $15 \mathrm{~min}$. Reference levels of salivary SIgA were obtained by analyzing samples from 20 healthy adults.

For analysis of total IgA by ELISA, an anti-human IgA antibody directed against the $\alpha$-chain (Dakopatts AB, Täby, Sweden) was used as coating antibody, enabling detection of all $\operatorname{IgA}$, including monomeric, polymeric, and SIgA. For detection of SIgA by ELISA, an anti-human SC antibody (Dakopatts $\mathrm{AB}$ ) was used, enabling detection of only SIgA. Alkaline phosphataseconjugated goat-anti-human-IgA antibodies (Sigma Chemical Co. Immunochemicals, Stockholm, Sweden) were used for detection. Detailed description of the methods is published elsewhere (4). Human IgA (Sigma Chemical Co. Immunochemicals) was diluted to a seven-step standard curve, ranging 40 to $2500 \mu \mathrm{g} / \mathrm{L}$ for total IgA and 16 to $1000 \mu \mathrm{g} / \mathrm{L}$ for SIgA. The limits of detection were $40 \mu \mathrm{g} / \mathrm{L}$ for total IgA and $32 \mu \mathrm{g} / \mathrm{L}$ for SIgA. The interassay coefficients of variations (CVs) were $10 \%$ for total IgA and $14 \%$ for SIgA. Total IgA and SIgA were detectable in all samples.

For detection of IgG antibodies in saliva, a human IgG ELISA quantitation kit was used (Bethyl Laboratories, Inc. Montgomery), according to the manufacturer. Human reference serum, containing $4 \mathrm{mg} / \mathrm{mL}$ of $\mathrm{IgG}$ antibodies, was included in the kit and used as a seven-step standard curve, ranging from 7.8 to $500 \mathrm{ng} / \mathrm{mL}$. All saliva samples were diluted 1:10 to $1: 1000$.

House dust samples. Two dust samples were collected from each household, one from the carpet and one from the child's mattress when the infants were between 6 and $12 \mathrm{mo}$ of age. A dust collector device, containing a $6 \mu \mathrm{m}$ pore size filter (ALK), was connected to a vacuum cleaner. The mattress, without sheets, and $2 \mathrm{~m}^{2}$ of the carpet were vacuum cleaned for $4 \mathrm{~min}$. The filters were stored in sterile plastic bags and kept at $-20^{\circ} \mathrm{C}$ until analysis.

The extractions and endotoxin analysis were performed as described in detail elsewhere with a chromogenic Limulus Amebocyte Lysate (LAL) assay

Table 1. The incidence of diarrhea, respiratory infections, otitis media, and antibiotic treatment during the first $2 y$ of life, and the length of exclusive and total breastfeeding in Estonian and Swedish children

\begin{tabular}{|c|c|c|c|c|c|}
\hline & $0-3 \mathrm{mo}$ & $3-6 \mathrm{mo}$ & $6-12 \mathrm{mo}$ & $12-24 \mathrm{mo}$ & Cumulative $0-24 \mathrm{mo}$ \\
\hline \multicolumn{6}{|l|}{ Diarrhea } \\
\hline Estonia & $41 / 106(37 \%)^{*}$ & $32 / 106(30 \%)^{(p=0.06)}$ & $59 / 106(56 \%)^{(p=0.07)}$ & $58 / 97(60 \%)$ & $90 / 106(85 \%)^{(p=0.10)}$ \\
\hline Sweden & $20 / 89(22 \%)^{*}$ & $15 / 83(18 \%)^{(p=0.06)}$ & $37 / 83(43 \%)^{(p=0.07)}$ & $43 / 83(52 \%)$ & $65 / 86(76 \%)^{(p=0.10)}$ \\
\hline \multicolumn{6}{|l|}{ Respiratory infections } \\
\hline Estonia & $32 / 110(29 \%) \dagger$ & $62 / 110(56 \%)$ & 99/109(91\%)末 & $95 / 102(93 \%) \ddagger$ & $109 / 109(100 \%) \ddagger$ \\
\hline Sweden & $42 / 89(47 \%) \dagger$ & $38 / 83(46 \%)$ & $43 / 86(50 \%) \ddagger$ & $37 / 83(45 \%) \ddagger$ & $72 / 87(83 \%) \ddagger$ \\
\hline \multicolumn{6}{|l|}{ Otitis media } \\
\hline Estonia & No data & No data & $24 / 109(22 \%)$ & $22 / 101(22 \%)^{*}$ & No data \\
\hline Sweden & $6 / 90(7 \%)$ & $5 / 84(6 \%)$ & $20 / 86(23 \%)$ & $31 / 83(37 \%)^{*}$ & $44 / 80(55 \%)$ \\
\hline \multicolumn{6}{|l|}{ Antibiotics } \\
\hline Estonia & No data & $26 / 110(24 \%)^{*}$ & $56 / 109(51 \%) \dagger$ & $51 / 100(51 \%)$ & $86 / 109(79 \%)$ \\
\hline Sweden & $6 / 88(7 \%)$ & $10 / 83(12 \%)^{*}$ & $23 / 83(28 \%) \dagger$ & $37 / 79(47 \%)$ & $50 / 74(68 \%)$ \\
\hline Breastfeeding & \multicolumn{3}{|c|}{ Exclusive breast feeding (mo) } & \multicolumn{2}{|c|}{ Total breast feeding (mo) } \\
\hline Estonia [mean (range)] & \multicolumn{3}{|c|}{$2.8(0.25-6.5) \ddagger$} & \multicolumn{2}{|c|}{$8.0(0.5-24)$} \\
\hline Sweden [mean (range)] & \multicolumn{3}{|c|}{$3.9(0-8.5) \ddagger$} & \multicolumn{2}{|c|}{$8.3(0.25-24)$} \\
\hline
\end{tabular}

Statistically significant differences are marked with bold.

$* p<0.05$.

$\dagger p<0.01$.

$\$ p<0.001$. 
Table 2. The incidence of allergic symptoms and SPT positivity in Estonian and Swedish children followed up from birth to 5 y of age

\begin{tabular}{|c|c|c|c|c|c|c|c|}
\hline & $0-3$ mo & $3-6$ mo & $6-12 \mathrm{mo}$ & $12-24 \mathrm{mo}$ & Cumulative $0-24$ mo & $5 \mathrm{y}$ & Cumulative $0-5 \mathrm{y}$ \\
\hline \multicolumn{8}{|l|}{ Allergy } \\
\hline \multirow[t]{4}{*}{ Estonia } & $3 / 109(3 \%)^{*}$ & 4/108 $(4 \%) \dagger$ & $8 / 109(7 \%)^{*}$ & $16 / 103(16 \%)^{(p=0.06)}$ & $18 / 105(17 \%)^{*}$ & $22 / 98(22 \%)^{(p=0.06)}$ & $24 / 98(24 \%)^{*}$ \\
\hline & $\mathbf{A D}(n=3)$ & $\mathbf{A D}(n=4)$ & $\mathbf{A D}(n=8)$ & $\mathrm{AD}(n=11)$ & $\operatorname{AD}(n=13)$ & $\mathrm{AD}(n=12)$ & $\mathbf{A D}(n=15)$ \\
\hline & & & & $\mathrm{AB}(n=6)$ & $\mathrm{AB}(n=6)$ & $\mathrm{AB}(n=10)$ & $\mathrm{AB}(n=10)$ \\
\hline & & & & & & $\operatorname{ARC}(n=7)$ & $\operatorname{ARC}(n=7)$ \\
\hline \multirow[t]{4}{*}{ Sweden } & $9 / 50(18 \%)^{*}$ & $11 / 49(22 \%) \dagger$ & $22 / 90(24 \%)^{*}$ & $24 / 86(28 \%)^{(p=0.06)}$ & $28 / 83(34 \%)^{*}$ & $26 / 73(36 \%)^{(p=0.06)}$ & $34 / 73(47 \%)^{*}$ \\
\hline & $\mathbf{A D}(n=9)$ & $\mathbf{A D}(n=10)$ & $\mathbf{A D}(n=21)$ & $\mathrm{AD}(n=21)$ & $\mathrm{AD}(n=25)$ & $\mathrm{AD}(n=19)$ & $\mathrm{AD}(n=29)$ \\
\hline & & $\mathbf{A B}(n=1)$ & $\mathbf{A B}(n=1)$ & $\mathrm{AB}(n=5)$ & $\mathbf{A B}(n=5)$ & $\mathrm{AB}(n=14)$ & $\mathrm{AB}(n=14)$ \\
\hline & & & & & & $\operatorname{ARC}(n=13)$ & $\operatorname{ARC}(n=13)$ \\
\hline \multicolumn{8}{|l|}{ SPT } \\
\hline Estonia & $5 / 109(5 \%)$ & $7 / 108(6 \%)^{*}$ & $7 / 109(6 \%)^{*}$ & $7 / 103(7 \%) \ddagger$ & $13 / 107(12 \%) \neq$ & $14 / 102(14 \%)^{(p=0.09)}$ & $21 / 102(21 \%)^{*}$ \\
\hline Sweden & $5 / 50(10 \%)$ & $10 / 49(20 \%)^{*}$ & $18 / 90(20 \%)^{*}$ & $16 / 86(19 \%) \ddagger$ & $22 / 86(26 \%) \ddagger$ & $17 / 69(24 \%)^{(p=0.09)}$ & $28 / 69(41 \%)^{*}$ \\
\hline
\end{tabular}

Clinical evaluations and SPTs were done at all follow-ups in Estonia, whereas in the Swedish children they were done either at 3 or 6 mo, and then at 12 and 24 mo and 5 y of age. Statistically significant differences are marked with bold.

$* p<0.01$.

$\dagger p<0.001$.

$\$ p<0.05$.

$\mathrm{AB}$, asthma bronchiale; $\mathrm{AD}$, atopic dermatitis; $\mathrm{ARC}$, atopic rhinoconjunctivitis.

(QCL-1000, Bio Whittaker, Walkersville, ND) (17). The lowest limit for quantitative determinations, for samples diluted 1:1000, was 50 endotoxin units $(\mathrm{EU}) / \mathrm{mL}$, corresponding to $0.50 \mathrm{EU} / \mathrm{mg}$ dust. Endotoxin analyses were performed on 98 Estonian and 68 Swedish dust samples. The median levels and the range of endotoxin in carpets were $26(0.5-376) \mathrm{EU} / \mathrm{mg}$ in Estonia and $13(0.5-1393) \mathrm{EU} / \mathrm{mg}$ in Sweden $(p<0.0001)$. The corresponding figures for mattresses were 28 (0.5-275) EU/mg in Estonia and 18 (0.5-99) EU/mg in Sweden $(p=0.004)$.

Statistics. As the concentrations of antibodies were not normally distributed, comparisons between unpaired groups were performed with the MannWhitney $U$ test and paired groups were analyzed using Wilcoxon-signed rank test. Correlations were calculated with Spearman correlation test. The $\chi^{2}$ test was used for comparisons of categorical variables. A probability level of $<0.05$ was considered to be statistically significant.

\section{RESULTS}

The levels of total IgA in saliva increased with age, both in Estonian and Swedish infants (Fig. 1A). The total IgA levels were higher in the Estonian infants at 3 mo, whereas at 2 y the levels were higher in saliva from Swedish children (Fig. 1A). At $5 \mathrm{y}$, the levels were similar in the two populations (Fig. 1A).

The levels of SIgA also increased with age in both populations, reaching adult levels at 5 y (Fig. 1B). The levels of SIgA were much higher in saliva from Estonian than Swedish children through the first 2 y of life, however. Similar SIgA levels were observed in Estonian and Swedish children only at $5 \mathrm{y}$ of age (Fig. $1 B$ ). The similar levels of total IgA and higher levels of SIgA are explained by the fact that most of the

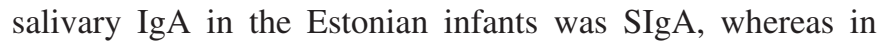
the Swedish infants the SIgA levels were markedly lower than the total IgA levels (Fig. 2). Thus, the SIgA/total IgA ratio was significantly lower in Swedish than Estonian children at 3, 6, 12, and 24 mo (Mann-Whitney $U$ test, $p<0.0001$ for all comparisons) but not at $5 \mathrm{y}$ of age.

Total IgG levels were analyzed in saliva collected at 12 mo and at $5 \mathrm{y}$ as a marker of passive transport over the epithelium. At 12 mo, the levels of total IgG correlated with the non-SIgA levels in the Swedish infants (rho $=0.51, p<0.0001)$ but not in the Estonian infants.

House dust endotoxin levels did not correlate with salivary IgA production, except for inverse correlations between the

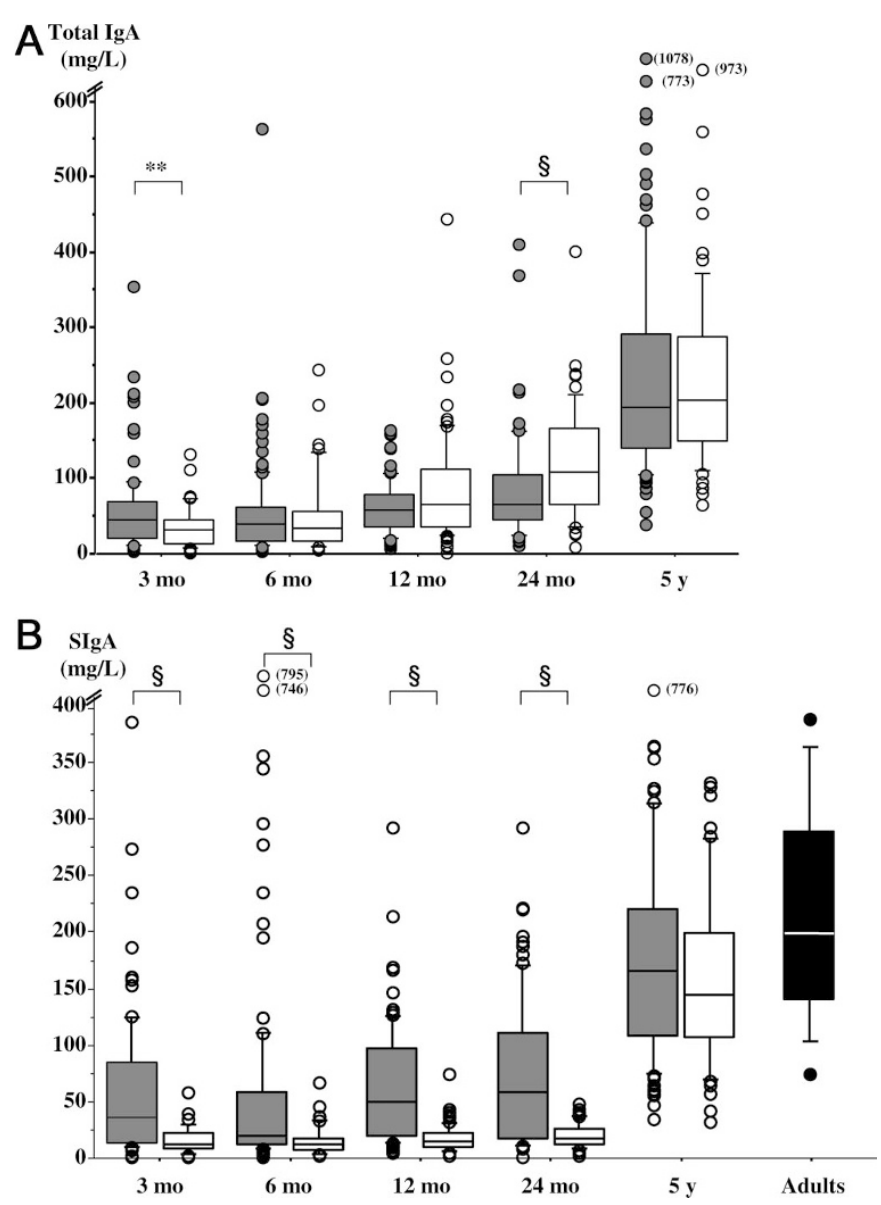

Figure 1. Salivary IgA levels (mg/L) in children at 3, 6, and $12 \mathrm{mo}$ and at 2 and $5 \mathrm{y}$ of age. (A) Total IgA levels in Estonian $(\square, n=100,106,91,78,99)$ and Swedish $(\square, n=39,37,77,65,60)$ children. (B) Levels of secretory (S) IgA in Estonian ( $\square, n=101,106,91,78,99)$ and Swedish $(\square, n=41,39$, $80,67,60)$ children and from 20 Swedish adults (ם). Salivary samples were collected from the Swedish children either at 3 or 6 mo, and then at 12 and 24 mo and $5 \mathrm{y}$ of age. The 10th, 25th, 50th, 75th, and 90th percentiles and outliers (circles) are indicated. ${ }^{*} p<0.01, \S p<0.001$.

levels in dust from mattresses and carpets and non-SIgA at 6 and 12 mo of age in the Swedish infants ( $r h o=-0.24$ to 0.48 , $p=0.01-0.048$ ). 


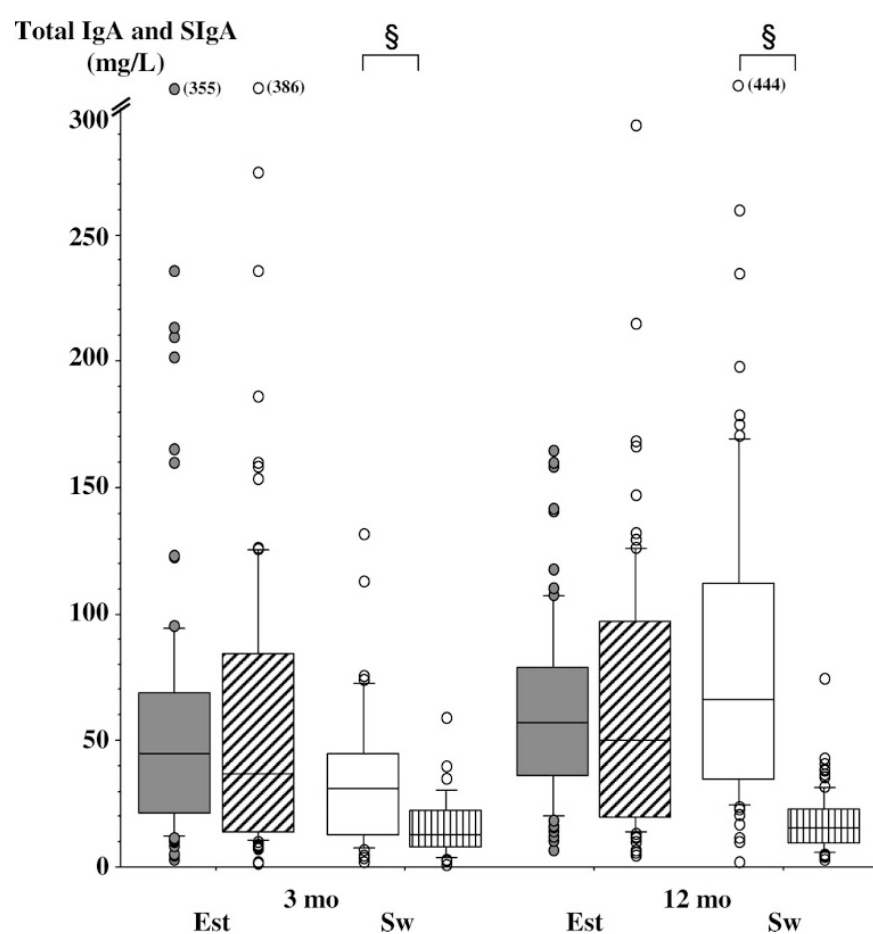

Figure 2. The total $\operatorname{Ig} A$ levels in Estonian $(\square, E s t)$ and in Swedish $(\square, S w)$ children compared with the SIgA levels in saliva (in Estonian (ד) and in Swedish $(\mathbb{D})$ children) at 3 and 12 mo of age, $n$ according to Fig. 1. The 10th, 25th, 50th, 75th, and 90th percentiles are indicated as well as outliers (circles). $\S p<0.001$.

Respiratory infections, i.e. common cold, cough, and wheeze, during infancy were more common in Estonian than in Swedish children, except during the first 3 mo of life (Table 1). Also diarrhea tended to be more common in Estonia during infancy, whereas the Swedish children tended to have more otitis. The Estonian children were more often treated with antibiotics during their first $12 \mathrm{mo}$. Respiratory infections between 3 and 6 mo of age were associated with higher SIgA levels at 6 mo in both Estonian and Swedish children. Similar results were observed for respiratory infections between 6 and 12 mo and SIgA levels at 12 mo in the Estonian children (data not shown). Diarrhea, otitis, and antibiotic treatment were not associated with salivary $\operatorname{Ig}$ A levels.

A lower proportion of Estonian than Swedish children attended day care before 2 y of age (20 versus 79\%, $p<$ $0.001, \chi^{2}$ test). In Estonia, $4.5 \%$ of the children (5/110) lived at $3 \mathrm{mo}$ of age in households where both parents smoked compared with $4.3 \%$ in Sweden (4/91, NS). No Estonian and two Swedish children lived in a household where the mother alone smoked (NS). The proportion of children with a smoking father and nonsmoking mother was higher in Estonia $(35 \%, 38 / 110)$ than Sweden $(4.3 \%, 4 / 91), p<0.001, \chi^{2}$ test. Day-care attendance and smoking were not related to the IgA and SIgA levels at any age neither in the Estonian nor in the Swedish children, however.

Among the Swedish sensitized infants, those with allergic symptoms during the first $2 \mathrm{y}$ of life had lower levels of SIgA at 3,6, and 12 mo than similarly sensitized infants without any clinical symptoms, with a similar trend at 24 mo of age (Fig. 3 ) but not at 5 y of age [median and interquartile ranges in

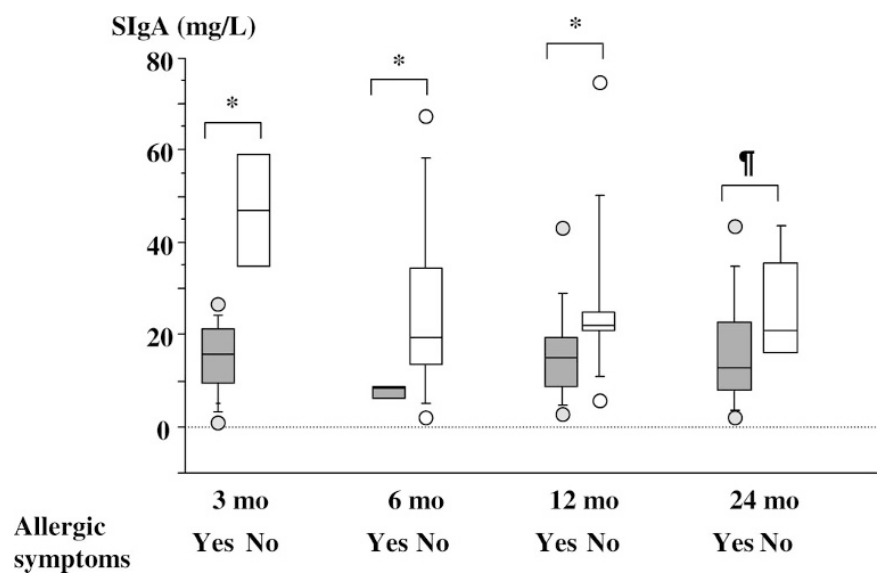

Figure 3. Secretory $(\mathrm{S}) \operatorname{IgA}(\mathrm{mg} / \mathrm{L})$ in saliva collected at 3, 6, 12, and $24 \mathrm{mo}$ of age from Swedish sensitized infants with $(\square, n=9,5,13$, and 10) and without ( $\square, n=4,8,10$, and 8 ) allergic symptoms during the first $2 \mathrm{y}$ of life. Sensitization was defined as at least one positive SPT and/or detection of circulating allergen-specific IgE antibodies. The 10th, 25th, 50th, 75th, and 90th percentiles and outliers (circles) are indicated. ${ }^{*} p<0.05$, and $\mathbb{I} p=0.11$.

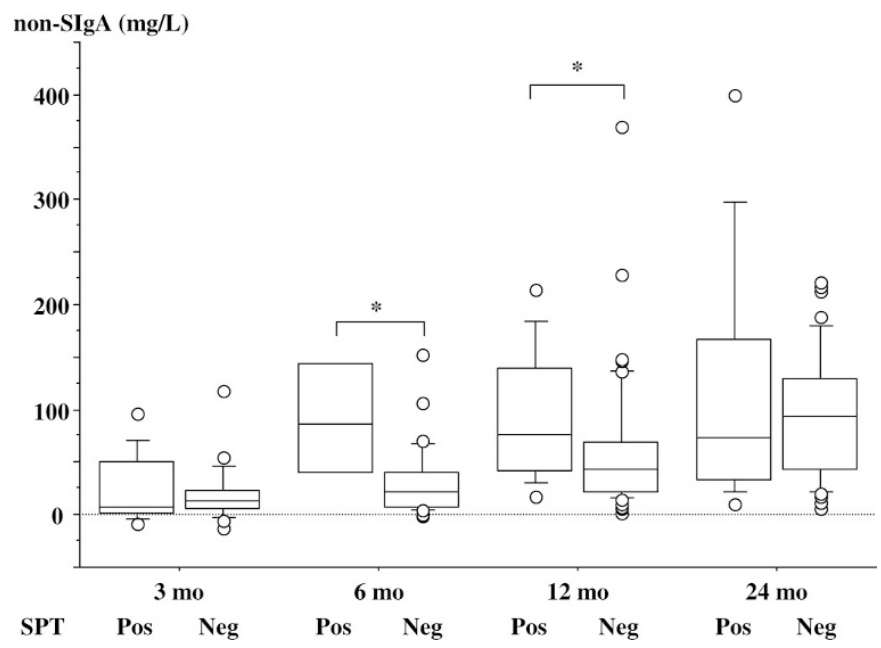

Figure 4. The levels of nonsecretory (S) IgA (the part of total IgA lacking the SC), in saliva collected at $3,6,12$, and 24 mo of age from Swedish infants with positive $(n=11,6,13,10)$ or negative $(n=24,26,54,44)$ SPTs during the first $2 \mathrm{y}$ of life. The 10th, 25th, 50th, 75th, and 90th percentiles and outliers (circles) are indicated. ${ }^{*} p<0.05$.

sensitized children with and without symptoms, 141 (90-187) and 176 (134-207) mg/L, respectively]. No such association was observed for allergic symptoms at $5 \mathrm{y}$ in the Swedish children, nor at any age in the Estonian children, possibly because of the low number of children with positive SPT and allergic disease among the latter (Table 2). Neither total IgA nor SIgA levels were associated with development of allergic disease or sensitization as such, however (data not shown), although non-SIgA levels, defined by subtracting the levels of SIgA from the levels of total IgA, were higher in Swedish SPT-positive than -negative children at 6 and 12 mo of age (Fig. 4). The non-SIgA levels at $5 \mathrm{y}$ of age were similar in SPT-positive and -negative children [median and interquartile ranges $53(20-100)$ and $53(25-88) \mathrm{mg} / \mathrm{L}$, respectively]. 


\section{DISCUSSION}

Mucosal IgA production increased with age, reaching adult levels at $5 \mathrm{y}$. In the Estonian children, most of the salivary IgA was in the secretory form at all ages, with an SC attached to the IgA dimer. In contrast, SIgA comprised a much lower proportion of total salivary IgA in the Swedish infants during the first $2 \mathrm{y}$ of life, indicating that a large proportion of their salivary IgA lacked an SC. At $5 \mathrm{y}$ of age, however, the levels of SIgA and total IgA were comparable also among the Swedish children.

At mucosal sites, such as the salivary glands, dimeric IgA antibodies synthesized in plasma cells beneath the epithelial basement membrane bind to the polymeric immunoglobulin receptor (pIgR) on the basolateral surface of the epithelial cells (1). The complex is transported to the apical surface, where the $\mathrm{pIgR}$ is cleaved to leave the extracellular IgAbinding component bound to the $\operatorname{IgA}$ molecule as the so-called $\mathrm{SC}$ (1). The pIgR-mediated transocytosis of IgA across the epithelium suggests that all $\operatorname{IgA}$ in the lumen of mucosal organs should be in the secretory form. The synthesis of the pIgR may for some reason be delayed in Swedish infants. A reduced pIgR-mediated IgA transport may allow a larger proportion of dimeric IgA to passively diffuse over the epithelium, resulting in the presence of non-SIgA in the salivary gland. Also, a reduced epithelial barrier function may cause increased mucosal leakiness (19). A certain microbial pressure may be mandatory for preservation of an intact mucosal barrier function (20). In support of our findings of non-SIgA in saliva of Swedish infants, both monomeric and SIgA were present in saliva of Australian children at least up to 12 mo of age (21). After $12 \mathrm{mo}$, a switch to only SIgA production was proposed (21).

Total IgG levels in saliva were analyzed at 1 and $5 \mathrm{y}$ of age as a marker of nonreceptor-mediated transocytosis of immunoglobulins over the epithelium. The correlation between total $\mathrm{IgG}$ and non-SIgA levels in the Swedish infants suggests that a large proportion of the IgA in their saliva was secreted without $\mathrm{pIgR}$ involvement. This was not the case in the Estonian children.

The expression of pIgR is modulated by microbes and microbial-derived products (22) and bacterial LPS and double-stranded RNA both upregulate the expression (23). The concentrations of bacterial endotoxin (i.e. LPS) in house dust were considerably higher in Estonian than Swedish homes (17). This may possibly explain the higher SIgA levels in the Estonian infants. This suggestion is supported by the inverse relation between house dust endotoxin levels and the proportion of non-SIgA in the Swedish infants. Furthermore, commensal intestinal bacteria, e.g. Bacteroides thetaiotaomicron, have been shown to upregulate the expression of the $\mathrm{pIgR}$ (24). Pronounced differences in the composition of the gut flora between Estonian and Swedish infants have previously been reported, with a more diverse flora in the former population (14). Moreover, an increased bifidobacterial diversity during the first 2 mo of life was associated with enhanced salivary SIgA levels in Swedish infants (25).
As one of the main functions of $\operatorname{SIgA}$ is to protect against mucosal infections by preventing adherence and penetration of microbes (1), low levels of SIgA could theoretically impose an increased susceptibility to infections. In this study, however, a history of infections early in life was associated with high SIgA levels, probably reflecting the stimulatory effect of the microbial pressure on mucosal immunity early in life.

High levels of salivary SIgA early in life seemed to protect sensitized children from developing clinical signs of allergy. This is in line with a previous report (4). Furthermore, we recently confirmed this observation in a cohort of 200 children followed from birth to $4 \mathrm{y}$ of age (26). The presence of SC enhances both the stability and effector functions of $\operatorname{IgA}(22)$. High mucosal SIgA levels could possibly interfere with the interaction between allergen and IgE antibodies in sensitized individuals, thereby preventing triggering of allergic inflammation and clinical symptoms. This notion is supported by animal models showing that mucosal $\operatorname{IgA}$ responses inhibit airway reactivity in sensitized mice (27-29). Also, induction of IgA to allergens during immunotherapy has been suggested to relate to the development of tolerance (30). High levels of non-SIgA may further reflect an immature and leaky mucosal membrane (19), allowing an uptake of allergens through the mucosa. The slow maturation of the salivary SIgA system in Swedish infants was associated with low house dust endotoxin levels and allergy development. This is in line with recent findings that high salivary IgA levels were related to early day-care attendance and less atopy in Australian children (31) and with the hypothesis that the allergy epidemic is caused by a decreased microbial exposure (9).

In conclusion, Swedish children show a markedly slower maturation of the salivary SIgA system than Estonian children, possibly as a consequence of the large differences in microbial pressure between the two countries. SIgA may limit allergy-mediated tissue damage at mucosal surfaces in sensitized individuals.

Acknowledgments. We thank the research nurse Lena Lindell for her enthusiastic work guiding the families through the study and all sampling procedures; Ulrika Bengtsson, AnneMarie Fornander, and Tiina Rebane for excellent technical assistance; and Dr. Karel Duchén for clinical evaluation. We also thank Professor Patrick Holt and Professor Per Brandtzaeg for critical reading and their valuable suggestions for improving the manuscript.

\section{REFERENCES}

1. Cerutti A, Chen K, Chorny A 2011 Immunoglobulin responses at the mucosal interfaces. Annu Rev Immunol 29:273-293

2. Cripps AW, Gleeson M, Clancy RL 1991 Ontogeny of the mucosal immune response in children. Adv Exp Med Biol 310:87-92

3. Hattevig G, Kjellman B, Björkstén B 1993 Appearance of IgE antibodies to ingested and inhaled allergens during the first 12 years of life in atopic and non-atopic children. Pediatr Allergy Immunol 4:182-186

4. Böttcher MF, Häggström P, Björkstén B, Jenmalm MC 2002 Total and allergenspecific immunoglobulin A levels in saliva in relation to the development of allergy in infants up to 2 years of age. Clin Exp Allergy 32:1293-1298

5. Kukkonen K, Kuitunen M, Haahtela T, Korpela R, Poussa T, Savilahti E 2010 High intestinal IgA associates with reduced risk of IgE-associated allergic diseases. Pediatr Allergy Immunol 21:67-73

6. Devenny A, Wassall H, Ninan T, Omran M, Daud Khan S, Russell G 2004 Respiratory symptoms and atopy in children in Aberdeen: questionnaire studies of a defined school population repeated over 35 years. BMJ 329:489-490 
7. Bråbäck L, Breborowicz A, Julge K, Knutsson A, Riikjärv MA, Vasar M, Björkstén B 1995 Risk factors for respiratory symptoms and atopic sensitisation in the Baltic area. Arch Dis Child 72:487-493

8. von Mutius E, Martinez FD, Fritzsch C, Nicolai T, Roell G, Thieman HH 1994 Prevalence of asthma and atopy in two areas of West and East Germany. Am J Respir Crit Care Med 149:358-364

9. Okada H, Kuhn C, Feillet H, Bach JF 2010 The 'hygiene hypothesis' for autoimmune and allergic diseases: an update. Clin Exp Immunol 160:1-9

10. Björkstén B, Sepp E, Julge K, Voor T, Mikelsaar M 2001 Allergy development and the intestinal microflora during the first year of life. J Allergy Clin Immunol 108:516-520

11. Penders J, Thijs C, van den Brandt PA, Kummeling I, Snijders B, Stelma F, Adams H, van Ree R, Stobberingh EE 2007 Gut microbiota composition and development of atopic manifestations in infancy: the KOALA Birth Cohort Study. Gut 56:661667

12. Wang M, Karlsson C, Olsson C, Adlerberth I, Wold AE, Strachan DP, Martricardi PM, Aberg N, Perkin MR, Tripodi S, Coates AR, Hesselmar B, Saalman R, Molin G, Ahrné S 2008 Reduced diversity in the early fecal microbiota of infants with atopic eczema. J Allergy Clin Immunol 121:129-134

13. Sjögren YM, Jenmalm MC, Böttcher MF, Björkstén B, Sverremark-Ekström E 2009 Altered early infant gut microbiota in children developing allergy up to 5 years of age. Clin Exp Allergy 39:518-526

14. Sepp E, Julge K, Vasar M, Naaber P, Björkstén B, Mikelsaar M 1997 Intestinal microflora of Estonian and Swedish infants. Acta Paediatr 86:956-961

15. von Mutius E, Vercelli D 2010 Farm living: effects on childhood asthma and allergy. Nat Rev Immunol 10:861-868

16. von Mutius E, Braun-Fahrländer C, Schierl R, Riedler J, Ehlermann S, Maisch S, Waser M, Nowak D 2000 Exposure to endotoxin or other bacterial components might protect against the development of atopy. Clin Exp Allergy 30:1230-1234

17. Böttcher MF, Björkstén B, Gustafson S, Voor T, Jenmalm MC 2003 Endotoxin levels in Estonian and Swedish house dust and atopy in infancy. Clin Exp Allergy 33:295-300

18. Voor T, Julge K, Böttcher MF, Jenmalm MC, Duchén K, Björkstén B 2005 Atopic sensitization and atopic dermatitis in Estonian and Swedish infants. Clin Exp Allergy $35: 153-159$

19. Turner JR 2009 Intestinal mucosal barrier function in health and disease. Nat Rev Immunol 9:799-809
20. Rakoff-Nahoum S, Paglino J, Eslami-Varzaneh F, Edberg S, Medzhitov R 2004 Recognition of commensal microflora by toll-like receptors is required for intestinal homeostasis. Cell 118:229-241

21. Cripps AW, Gleeson M, Clancy RL 1989 Molecular characteristics of IgA in infant saliva. Scand J Immunol 29:317-324

22. Kaetzel CS 2005 The polymeric immunoglobulin receptor: bridging innate and adaptive immune responses at mucosal surfaces. Immunol Rev 206:83-99

23. Schneeman TA, Bruno ME, Schjerven H, Johansen FE, Chady L, Kaetzel CS 2005 Regulation of the polymeric Ig receptor by signaling through TLRs 3 and 4: linking innate and adaptive immune responses. J Immunol 175:376-384

24. Hooper LV, Wong MH, Thelin A, Hansson L, Falk PG, Gordon JI 2001 Molecular analysis of commensal host-microbial relationships in the intestine. Science 291:881-884

25. Sjögren YM, Tomicic S, Lundberg A, Böttcher MF, Björkstén B, SverremarkEkström E, Jenmalm MC 2009 Influence of early gut microbiota on the maturation of childhood mucosal and systemic immune responses. Clin Exp Allergy 39:18421851

26. Sandin A, Björkstén B, Böttcher MF, Englund E, Jenmalm MC, Bråbäck L 2011 High salivary secretory IgA antibody levels are associated with less late-onset wheezing in IgE-sensitized infants. Pediatr Allergy Immunol 2:477-481

27. Schwarze J, Cieslewicz G, Joetham A, Sun LK, Sun WN, Chang TW, Hamelmann E, Gelfand EW 1998 Antigen-specific immunoglobulin-A prevents increased airway responsiveness and lung eosinophilia after airway challenge in sensitized mice. Am J Respir Crit Care Med 158:519-525

28. Hajek AR, Lindley AR, Favoreto S Jr, Carter R, Schleimer RP, Kuperman DA 2008 12/15-Lipoxygenase deficiency protects mice from allergic airways inflammation and increases secretory IgA levels. J Allergy Clin Immunol 122:633-639.e3

29. Smits HH, Gloudemans AK, van Nimwegen M, Willart MA, Soullie T, Muskens F, de Jong EC, Boon L, Pilette C, Johansen FE, Hoogsteden HC, Hammad H, Lambrecht BN 2009 Cholera toxin B suppresses allergic inflammation through induction of secretory IgA. Mucosal Immunol 2:331-339

30. Pilette C, Nouri-Aria KT, Jacobson MR, Wilcock LK, Detry B, Walker SM, Francis JN, Durham SR 2007 Grass pollen immunotherapy induces an allergen-specific IgA2 antibody response associated with mucosal TGF-beta expression. J Immunol 178:4658-4666

31. Ewing P, Otczyk DC, Occhipinti S, Kyd JM, Gleeson M, Cripps AW 2010 Developmental profiles of mucosal immunity in pre-school children. Clin Dev Immunol 2010:196785 